\title{
Structure of liquid alloys of the Au-Si and Au-Ge systems
}

\author{
R M Waghorne, V G Rivlin and G I Williams \\ Fulmer Research Institute Limited, Stoke Poges, Slough, Buckinghamshire SL2 4QD
}

Received 2 October 1975

\begin{abstract}
A study of the liquid alloys of the simple eutectic systems $\mathrm{Au}-\mathrm{Si}$ and $\mathrm{Au}-\mathrm{Ge}$ at selected compositions has demonstrated a pattern of behaviour very similar to that seen in the related gold-based system $\mathrm{Au}-\mathrm{Sn}$. The sharp $\mathrm{x}$ ray diffraction profile of $\mathrm{Au}-\mathrm{Ge}$ liquid alloys at the gold-rich end demonstrates that the structure, like that of pure $\mathrm{Au}$, is simple, close-packed but with a mean closest distance for neighbouring atoms smaller than that for liquid $\mathrm{Au}$ or $\mathrm{Ge}$. This result is also obtained for liquid $\mathrm{Au}-\mathrm{Si}$ alloys. The packing in the liquid phase can only be interpreted in terms of A-B bonding, i.e. unlike atom interaction, a feature attributed to a high electrochemical factor. With higher $\mathrm{Ge}$ content, the $\mathrm{x}$ ray diffraction profile broadens in a manner consistent with a more open liquid structure. We account for the latter in terms of the increasing influence of $\mathrm{Ge}-\mathrm{Ge}$ nearest neighbour packing. This model is straightforward in reconciling all observations of the liquid, but could not have been predicted from the solid phase structures of either $\mathrm{Au}-\mathrm{Si}$ or $\mathrm{Au}-\mathrm{Ge}$ where $\mathrm{A}-\mathrm{A}$ and $\mathrm{B}-\mathrm{B}$ bonding predominates. The liquid state has thus been shown to exhibit bonding behaviour distinct from the solid, and contrary to a commonly held assumption, its structure is not merely a reflection of solid state bonding. This disparity accounts for the anomalous solidification behaviour of the eutectic alloys, including expansion on solidification.
\end{abstract}

\section{Introduction}

The structure of the liquid state for most metals is notoriously difficult to define in rigorous terms. Progress in recent years has been confined to the 'simple' metals such as the group $1 \mathrm{~A}$ and $1 \mathrm{~B}$ metals which give $\mathrm{x}$ ray diffraction profiles that can adequately be accounted for by the simple, random, close-packed liquid model in the same way as the inert gas liquids (Ashcroft and Lekner 1966, Breuil and Tourand 1970). However, in the main, the $x$ ray diffraction profiles of liquid metals give evidence of structures deviating from the random model (Furukawa et al 1963, Rodriguez and Pings 1965, Isherwood et al 1972). The situation is complicated further when alloys are examined, and it is evident that in these cases the liquids are not only far from simple but that there is a strong dependence of liquid structure on composition. The experimental data for such alloys is now well established (Waghorne et al 1967, Kaplow et al 1966, Halder and Wagner 1967), but the literature still has sharp divergences of opinion on how such data should be interpreted. In particular, there is an understandable tendency to look for correlations between the structure of the liquid state and the equilibrium behaviour of the underlying solid phases. When there are no intermediate phases as in simple eutectic systems which segregate to A-A and B-B in the solid, the liquid is often considered to be similarly segregated with like atom clusters (Kumar and Sivaramakrishnan 1969a and b). Likewise, when 
one or more intermediate phases are present as in the Au-Sn system, it has been suggested that the liquid phase retains a 'memory' of the solid structure like that of the interatomic compound AuSn, diluted by either Au or Sn according to composition (Kaplow et al 1966).

It is the purpose of this investigation to show that while some correlations between liquid and solid phases do exist, there can be significant differences in local bonding. Evidence is presented for the existence of bonding of unlike atoms in the liquid phase of the simple eutectic alloy systems $\mathrm{Au}-\mathrm{Ge}$ and $\mathrm{Au}-\mathrm{Si}$ which is in direct contrast to the like-atom clustering which occurs in the corresponding crystalline solids. The interpretation is advanced on the basis of the $\mathrm{x}$ ray diffraction profiles of the liquid phase of these alloys, and on the observation of a volume expansion which is obtained on solidification of the alloys of eutectic composition. This expansion cannot be explained on the basis of a liquid structure which consists solely of a simple mixing of $\mathrm{A}-\mathrm{A}$ and $\mathrm{B}-\mathrm{B}$ like-atom clusters.

\section{Experimental methods}

\subsection{X ray diffraction}

2.1.1. Apparatus. For detailed descriptions of the method used to obtain $\mathrm{x}$ ray patterns from liquid metal surfaces the reader is referred to previous papers from these laboratories (Orton et al 1960, Furukawa et al 1963). The essential features are the use of a monochromatic $\mathrm{Cu} \mathrm{K}_{x} \times$ ray beam with Bragg-Brentano focusing geometry, to eliminate absorption errors, and the maintenance of a purified hydrogen atmosphere to minimize surface contamination of the liquid alloys. The purification procedure was the same as that used by Furukawa et al (1963), with the addition of a silverpalladium diffusion tube connected between the gas-line and camera.

2.1.2. Specimen preparation. Spectroscopically-pure gold grain (Johnson Matthey) and transistor grades of germanium (Bradhurst Co Ltd) and silicon (Du Pont Ltd) were used. Weighed amounts of these materials in the appropriate proportions were induction melted together in vacuo and each liquid alloy cast in an alumina crucible. Three alloy specimens were made in this way, nominal compositions Au $25 \mathrm{at} \% \mathrm{Ge}$, Au50at $\% \mathrm{Ge}$, and Au18.5at $\% \mathrm{Si}$.

2.1.3. Operating procedure. Each specimen was cleaned and placed in a graphite crucible inside the $x$ ray camera. After sealing and evacuating at a pressure of $10^{-4}$ Torr over a few hours, the camera vacuum line was closed and hydrogen admitted. The specimen was not melted until at least one hour after the commencement of hydrogen flow and it was then aligned to the diffractometer axis.

$\mathrm{X}$ ray counts were recorded from the diffracted beam at values of Bragg angle from $12^{\circ}$ to $65^{\circ}$. Counts were made at specific intervals of one degree except in the region of the main intensity peak where the intervals were $30^{\prime}$ or $15^{\prime}$. At least two counts were obtained at each angular position and, generally, five or more in the region of the main peak.

2.1.4. Treatment of $x$ ray intensity data. The recorded $x$ ray intensities, obtained as a function of $\sin \theta / \hat{\lambda}$ were corrected for lost counts, background counts and for 
polarization effects occurring at both the monochromator and liquid metal surface. At values of $s / 4 \pi$ below 0.13 the observed intensity was extrapolated smoothly to zero. Normalization to electron units was then carried out according to a method developed in these laboratories. In this the matching factor $K$ was obtained from the formula (Waghorne 1967, unpublished results).

$$
K=\frac{K_{1}-K_{2}}{D_{1}(r)-D_{2}(r)} \frac{2}{\pi r^{2}}\left[\sin \left(s_{\mathrm{M}} r\right)-s_{\mathrm{M}} r \cos \left(s_{\mathrm{M}} r\right)\right] \quad \text { evaluated at } r=0.1 \AA
$$

where $K_{1}$ and $K_{2}$ are unequal approximations to the value of $K, D_{1}(r)$ and $D_{2}(r)$ are the corresponding values of the atomic distribution function $D(r)$ defined below and $s_{\mathrm{M}}$ is the maximum value of $s=4 \pi \sin \theta / \lambda$ for which experimental intensities were measured. Radial distribution functions were then calculated using standard procedures from the expression

$$
r D(r)=\frac{2 r}{\pi} \int_{0}^{s_{\mathrm{M}}} \operatorname{si}(s) \sin s r \mathrm{~d} s
$$

where $i(s)$ is the total interference function. Errors due to approximations in this treatment are dealt with adequately elsewhere (Klug and Alexander 1954, Furukawa et al 1963).

\subsection{Volume change on solidification}

Some attempts have been made to measure the volume change on solidification of the eutectic alloys, Au25at $\% \mathrm{Ge}$ and Au18.5at $\%$ Si (which according to Heath (1961) has been shown to be the eutectic composition). Weighed amounts of an alloy were contained in silica tubing of known diameter. The alloy was melted by means of a small furnace tube, a narrow section of which was transparent to enable a view of the liquid alloy. The height of the liquid level was noted and the alloy then allowed to cool slowly. The solidification process invariably resulted in a cracking of the crucible and a pimpled appearance of the free surface of the alloy. Consequently no precise measurements of the volume expansion could be made. Approximate values were obtained however, and these are given in $\$ 3.3$ below.

\section{Results}

\subsection{Diffraction peak profiles}

The intensity pattern of the Au25at $\%$ Ge specimen was obtained at $425^{\circ} \mathrm{C}$ and that for the Au50at $\% \mathrm{Ge}$ specimen at $663{ }^{\circ} \mathrm{C}$. The Au18.5at $\% \mathrm{Si}$ alloy was examined at $390^{\circ} \mathrm{C}$. Corrected patterns, normalized to electron units, are shown in figures 1 and 2. Data obtained from the $x$ ray diffraction patterns, and the radial distribution curves derived from these are summarized in table 1.

The $x$ ray intensity pattern obtained from the alloy Au25at $\% \mathrm{Ge}$ has its main peak maximum at $s / 4 \pi=0.217$. This value is higher than that for either pure $\mathrm{Au}$ $(0 \cdot 210$, Pfannenschmid 1960) or pure Ge $(0 \cdot 200$, Isherwood et al 1972) and consequently is higher than the value calculated for a simple mixture of liquid $\mathrm{Au}$ and liquid $\mathrm{Ge}$ (table 1). Furthermore the intensity pattern has a sharp, almost symmetrical, main peak which is similar to that for pure gold. The coordination, 


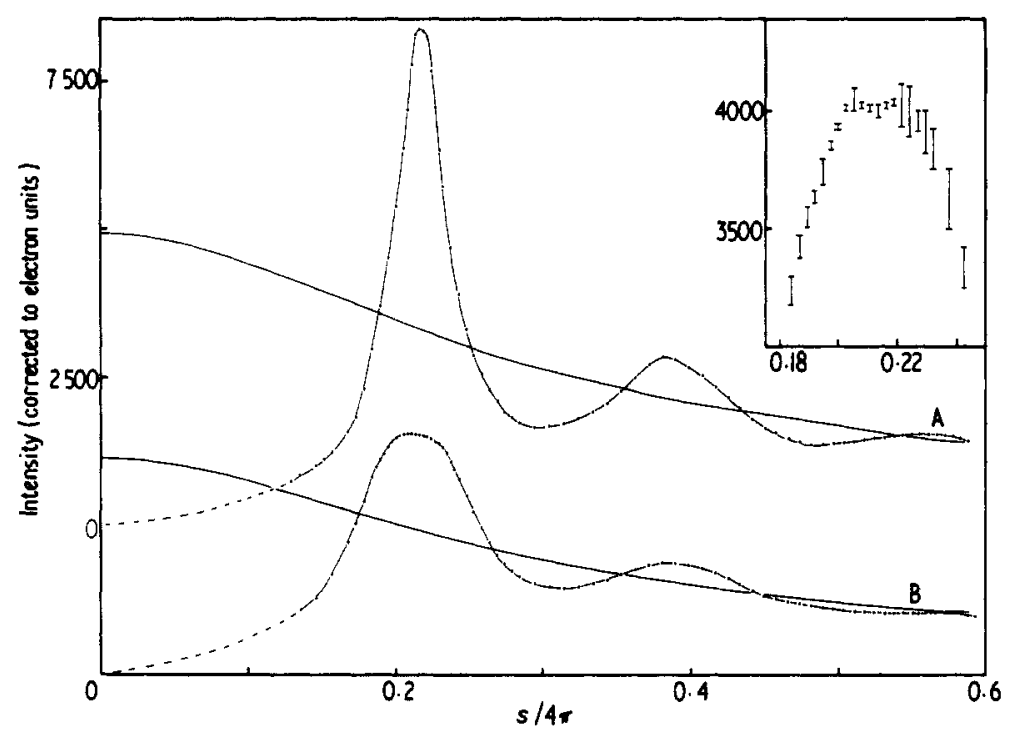

Figure 1. Diffraction profiles for liquid $\mathrm{Au}-\mathrm{Ge}$ alloys. A: Au25at $\% \mathrm{Ge}$ at $425^{\circ} \mathrm{C}$; B: Aus0at $\%$ Ge at $663^{\circ} \mathrm{C}$. Inset shows a partial pattern from the main peak region for Aus0at $\% \mathrm{Ge}$ at $640^{\circ} \mathrm{C}$.

derived from the corresponding radial distribution curve, is 10.6 near neighbours. Thus it can be stated that the liquid alloy Au25at $\% \mathrm{Ge}$ has a simple close-packed structure, similar to that for elemental liquid $\mathrm{Au}$ and to the liquid alloy Au25at $\% \mathrm{Sn}$ (Waghorne et al 1967).

The main peak of the intensity pattern from the alloy Au $50 \mathrm{at} \% \mathrm{Ge}$ is quite different. It is very broad and almost flat-topped, the plateau extending from $s / 4 \pi=0.203$ to $0 \cdot 225$. A partial pattern from the main peak region alone was obtained at $640^{\circ} \mathrm{C}$ and showed a slight tendency for the main peak to split into two components of almost equal intensity (figure 1, inset). This effect is analogous to that seen in the $x$ ray profiles of liquid alloys Au50at $\% \mathrm{Sn}, \mathrm{Cu} 45 \cdot 5 \mathrm{at} \% \mathrm{Sn}$, and Au66.7at $\%$ In (Waghorne et al 1967), and lends itself to the same interpretation as set out in the discussion.

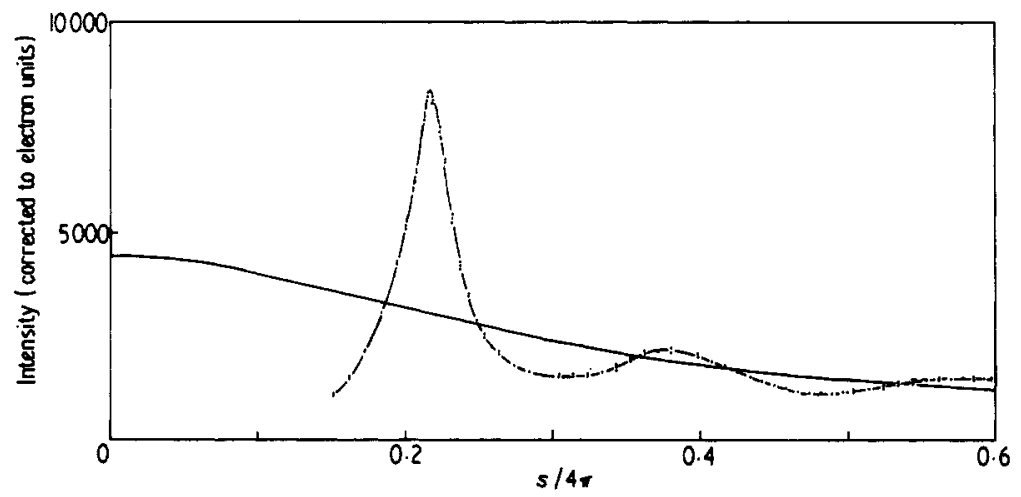

Figure 2. Diffraction profile for liquid Au-Si eutectic alloy Au $18.5 \mathrm{at} \% \mathrm{Si}$ at $390^{\circ} \mathrm{C}$. 
Table 1. $\mathrm{X}$ ray diffraction data for liquid $\mathrm{Au}-\mathrm{Ge}$ and $\mathrm{Au}-\mathrm{Si}$ alloys.

\begin{tabular}{|c|c|c|c|c|}
\hline $\begin{array}{l}\text { Alloy } \\
\text { composition } \\
\left(\mathrm{at}^{\circ} \mathrm{o}\right)\end{array}$ & $\begin{array}{l}\text { Position of } \mathrm{m} \\
\text { first diffractio } \\
\text { Observed }\end{array}$ & $\begin{array}{l}\text { mum intensity of } \\
\text { eak }(s / 4 \pi) \\
\text { Calculated }+ \text { for } \\
\text { simple mixing }\end{array}$ & $\begin{array}{l}\text { Mean distance } \\
\text { of closest } \\
\text { interatomic } \\
\text { approach }(\AA)\end{array}$ & $\begin{array}{l}\text { Coordination } \\
\text { number } \\
\text { of nearest } \\
\text { neighbours }\end{array}$ \\
\hline Au81.5:Si18.5 & 0.217 & $0.211+$ & $\sim 2.85$ & $>10$ \\
\hline Au75:Ge25 & $0 \cdot 217$ & 0.207 & $2 \cdot 87$ & $10 \cdot 6$ \\
\hline Au50:Ge50 & $0.203-0.225$ & 0.205 & $2 \cdot 87$ & $8 \cdot 3$ \\
\hline
\end{tabular}

†Values for the pure elements are taken from the literature: $A u$ at $s / 4 \pi=0.210$ (Pfannenschmid 1960); Ge at $s / 4 \pi=0.200$ (Isherwood et al 1972); Si at $s / 4 \pi=0.215$ (Waseda and Suzuki 1975).

The results for Au18.5at $\% \mathrm{Si}$ (the eutectic composition) gave a sharp diffraction profile similar to that of $\mathrm{Au} 25 \mathrm{at} \% \mathrm{Ge}$, and the main peak position again occurs at a higher value of $s / 4 \pi$ than for pure gold.

\subsection{Radial distribution functions}

The diffraction patterns of $\mathrm{Au} 25 \mathrm{at} \% \mathrm{Ge}$ and $\mathrm{Au} 50 \mathrm{at} \% \mathrm{Ge}$ (figure 1) have been analysed to obtain the corresponding radial distribution functions, shown in figure 3 . It is evident that while the curve for the Au25at \% Ge alloy continues to show oscillations about the mean radial density at $10 \AA$, that for the equiatomic alloy has only two

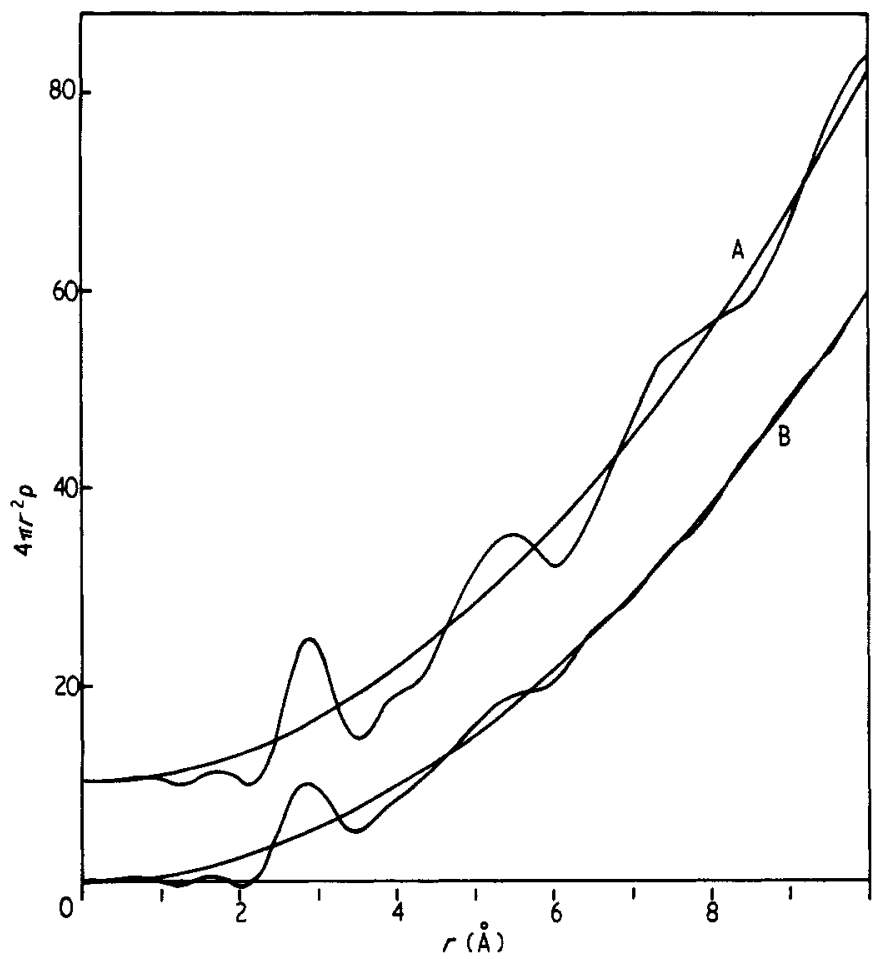

Figure 3. Radial distribution curves for liquid Au-Ge alloys. A: Au25at $\%$ Ge at $425^{\circ} \mathrm{C}$; B: Aus0at $\%$ Ge at $663^{\circ} \mathrm{C}$. 
distinct maxima, the deviation from the mean curve being very small for $r>6.5 \AA$. The mean distance of closest interatomic approach is the same for both alloys (table 1), and is marginally shorter than that for pure Au.

\subsection{Volume change on solidification}

The method used to measure the volume change on solidification of the eutectic alloys did not give accurate results because of the difficulty in containing the alloy due to cracking of the crucible during solidification. The measurements made indicated that the liquid phase of the Au25at $\%$ Ge alloy was some $5 \%$ smaller in volume, or greater in density by the same amount, than the solid phase at this composition.

For the Aul 8.5 at $\% \mathrm{Si}$ alloy an oxide skin was formed during the experiments, which also interfered with the measurements. The expansion on solidification of this alloy is estimated to be $1-2 \%$.

\section{Discussion}

\subsection{Methods of analysis of diffraction profiles}

The partial interference functions which describe the contribution of $\mathrm{A}-\mathrm{A}, \mathrm{A}-\mathrm{B}$ and B-B correlations to the total diffraction profile have been calculated by previous workers for selected alloy systems. There are two methods. The more accurate method is to perform three diffraction experiments on one alloy composition, using $\mathrm{x}$ ray and neutron sources (Keating 1963, Enderby et al 1966). This method, though precise, is limited in its applications chiefly owing to the unsuitability of isotopes in many systems for the neutron scattering experiment. The alternative is to carry out diffraction experiments for three different alloy compositions using one radiation source. The latter method necessarily involves making the assumption that the three partial functions for $\mathrm{A}-\mathrm{A}, \mathrm{A}-\mathrm{B}$ and $\mathrm{B}-\mathrm{B}$ correlations are independent of composition. While this assumption may be a reasonable one over a limited composition range, it cannot be correct over the whole range when the packing of atoms in the two components $\mathrm{A}$ and $\mathrm{B}$ are different. This point emerges quite clearly from a recent study of liquid alloys of the $\mathrm{Cu}-\mathrm{Ge}$ system (Isherwood and Orton 1972). In the present work, we have a similar disparity of packing between the components $\mathrm{Au}$ and $\mathrm{Ge}$, and so it is not accurate to derive the partial correlation functions for these systems with the information available at the compositions examined. Thus the deductions in this paper are based solely on the total diffraction profiles of the alloys and those of the liquid elements.

\subsection{Liquid alloys of $A u$ with group IVB elements}

The $\mathrm{x}$ ray results of $\mathrm{Au}-\mathrm{Si}$ and $\mathrm{Au}-\mathrm{Ge}$ liquid alloys fit the pattern established in these laboratories for other binary systems $\mathrm{A}-\mathrm{B}$, where ' $\mathrm{A}$ ' is one of the noble metals, $\mathrm{Cu}, \mathrm{Ag}$ or $\mathrm{Au}$ and 'B' an element from group IIIB (Al, Ga, In) or IVB (Sn) (Orton 1964, Waghorne et al 1967). In particular, there is a distinct correspondence between the results for $\mathrm{Au}-\mathrm{Sn}$ and the results in this paper. This may be expected to follow from the close chemical similarity of the B components, $\mathrm{Si}, \mathrm{Ge}$ and $\mathrm{Sn}$. The liquid alloys of Au25at $\% \mathrm{Ge}$ and $\mathrm{Au} 18.5 \mathrm{at} \% \mathrm{Si}$ have been shown to give simple liquid diffraction profiles and, as for Au25at \% Sn, the mean shortest distance of interatomic 
approach is in each case less than that in pure liquid Au. Likewise the coordination number is $10-11$ atoms. Consequently the liquid alloys, at these compositions, can be interpreted as simple close-packed structures like that of pure Au. Further addition of the B element gives rise to non-simple diffraction profiles (e.g. the composition $A 50 \mathrm{at} \% \mathrm{~B}$ ) which correspond to more open structures. It is very significant that metastable close-packed structures have been retained in the solid state by rapid quenching of liquids from these eutectic systems (Jones 1973).

\subsection{Relevant previous models of liquid alloy structures}

Much of the previous work on liquid alloy structures has attempted to interpret the liquid phase in terms of the underlying solid phase structures. For the present work it is important to note that the $\mathrm{Au}-\mathrm{Si}$ and $\mathrm{Au}-\mathrm{Ge}$ alloy systems are simple eutectics with no equilibrium intermetallic phases, whereas the structurally similar liquid alloys in the Au-Sn system have equilibrium solid compounds.

4.3.1. Solid compound model. One interpretation of the $\mathrm{x}$ ray results for liquid alloys of the Au-Sn system, proposed by Kaplow et al (1966), is based on the retention of the structure of the AuSn interatomic compound into the liquid state, which is diluted in proportion by $\mathrm{Au}$ or $\mathrm{Sn}$ atoms according to composition. Such an explanation, however, cannot be postulated for the $\mathrm{Au}-\mathrm{Si}$ and $\mathrm{Au}-\mathrm{Ge}$ liquid alloys as there is no such compound on which to base the model.

4.3.2. Eutectic segregation model. A number of simple eutectic systems have been investigated by means of centrifuging to segregate the liquid (Kumar and Sivaramakrishnan $1969 \mathrm{a}, \mathrm{b}$ ). The results so obtained have been interpreted as evidence for segregation of like-atom clusters in the liquid phase as well as in the solid. $\uparrow$ The segregation model however would predict a liquid diffraction profile which was merely a simple proportionate weighted sum of the profiles of the two component liquids. In $\mathrm{Au}-\mathrm{Ge}$ this model is inapplicable, as it would not give rise to a simple liquid profile at the Au25at $\%$ Ge composition.

This model also suggests that the densities of these liquid alloys could be calculated from the densities of the pure components. We have carried out such calculations for the liquid $\mathrm{Au}-\mathrm{Ge}$ alloys and compared the values obtained with the corresponding values for the solid phase. Available data show Au to expand $5.1 \%$ on melting (Ubbelohde 1965), while Ge contracts at most 12\% (Powell 1967). It was found that over most of the composition range $(>30 \mathrm{at} \% \mathrm{Ge})$ the liquid phase is expected to have a greater density than the corresponding solid, while in the Au-rich liquids $(<30 \mathrm{at} \% \mathrm{Ge})$ the reverse is the case. Thus according to the model of simple mixing of the two components, one would anticipate a decrease in volume on solidification at the Au25at $\% \mathrm{Ge}$ composition.

Our work has shown that this is not the case and that an expansion of some $5 \%$ takes place on solidification (\$3.3). Clearly this fundamental disparity between the liquid and solid phases of these alloys cannot be accounted for unless some degree of preferred bonding between unlike atoms is introduced into the model of the liquid state. Thus neither of the above models can be considered to be consistent with our experimental observations.

† Evidence for unlike atom clustering by means of liquid centrifuging is limited to the system Al-Cu (Singh and Kumar 1966), for which a number of solid state compounds exist. 
4.3.3. Model requirements. The similarity between the sets of diffraction data for the systems $\mathrm{Au}-\mathrm{Sn}, \mathrm{Au}-\mathrm{Ge}$ and $\mathrm{Au}-\mathrm{Si}$ in the liquid state indicates that their structure can all be interpreted by substantially the same model. This observation can also be applied to the results for liquid alloys of $\mathrm{Cu}-\mathrm{Sn}$ (Enderby et al 1966, Orton 1964), Ag-Sn (Halder and Wagner 1967) and the recent work on $\mathrm{Cu}-\mathrm{Ge}$ (Isherwood and Orton 1972). The model should be based on a close-packed simple liquid structure for the Au-rich (IB rich) compositions but should deviate from this before $50 a t \%$ of the IVB element is present. Further, it must be independent of the structures of the solid state. Finally it must include some degree of binding between unlike atoms in order to account for the greater density of the liquids of the $\mathrm{Au}-\mathrm{Ge}$ and $\mathrm{Au}-\mathrm{Si}$ eutectic alloys when compared with the corresponding solids.

It should be noted that an essential difference exists between the structures of the pure component element liquids of, on the one hand, the IB group and those of the IVB elements (excluding lead which, according to Kaplow et al (1965), is itself a simple close-packed highly coordinated liquid).

\subsection{Proposed model for the liquid packing in IB-IVB alloy systems}

In the following we shall refer to $\mathrm{A}$ for the IB components $\mathrm{Cu}, \mathrm{Ag}$ and $\mathrm{Au}$, and B for the IVB components Si. Ge and Sn. except where specifically quoted.

One essential feature of our proposed model is the existence of close packing in the liquid alloys of the A-B systems in the composition range $0-20 / 25 \mathrm{at} \%$ of the B element. Further increase of the concentration of the B component introduces a more open packing. This gradual trend towards a looser (lower coordinated) packing of atoms is continued across the rest of the composition range to that of the pure B element, where the liquid structure is certainly non-simple (Furukawa et al 1963, Isherwood et al 1972. Waseda and Suzuki 1975). It is evident that, as the proportion of B-B interactions must increase with the concentration thereof, the appearance of the open packing is associated with these B-B like-atom, interactions. Thus the existence of close packing at the lower $B$ concentrations $(<25 a t \%)$ implies that the B-B interactions are minimal in this composition range. That is the close packing effectively accommodates the B atoms in 'solution', a liquid counterpart of solid solution. The logical conclusion of this argument and the second essential feature of our proposed model is the existence of A-B type bonding in the close-packed liquid alloys. One consequence of this model would be to generate the observed disparity between the liquid and solid structures in the eutectic alloys. Again the high electrochemical factor in the Au-IVB systems would favour such A-B bonding.

The presence of stable interatomic compounds in the solid phase of many of the IB-IVB alloy systems, in the range of compositions $0-20 / 25 \mathrm{at} \%$ of the IVB element, is not inconsistent with this model of the liquid state. All such alloys have close-packed structures in both liquid and solid phases. Interatomic compounds such as $\epsilon$, distorted hexagonal (e.g. $\mathrm{Ag}_{3} \mathrm{Sn}$ ), $\zeta$ hexagonal (e.g. $\mathrm{Cu}_{5} \mathrm{Ge}$ ) are close packed and exhibit unlike-atom bonding. The systems of $\mathrm{Au}-\mathrm{Ge}, \mathrm{Au}-\mathrm{Si}, \mathrm{Ag}-\mathrm{Ge}$ and $\mathrm{Ag}-\mathrm{Si}$, where no stable compounds are formed will exhibit the same tendency for close packing but only in the liquid phase.

This model of the liquid structure for these alloy systems meets all the requirements set out above, and provides an explanation for the incidence of many experimentally observed changes in the physical properties at or around the 20/25at $\%$ B composition (Mott 1967). The compositions at which these changes occur correlate 
approximately with the maximum proportion of B atoms which can be accommodated in the close packed arrangement. In addition, recent calculations of compressibility in liquid copper-tin alloys have been interpreted to show that $\mathrm{Cu}-\mathrm{Sn}$ correlations are favoured over $\mathrm{Cu}-\mathrm{Cu}$ and $\mathrm{Sn}-\mathrm{Sn}$ correlations for compositions near to $75 \mathrm{at} \% \mathrm{Cu}$ (Turner et al 1973), in agreement with the proposed model.

It is also worth noting that the model is not dissimilar to that proposed initially by Hume-Rothery and Anderson (1960) for eutectic alloys, which was designed to account for the fact that particular compositions seem to be preferred for the eutectic point. While their model is too rigid to be entirely satisfactory for a liquid, it does include the idea that solute atoms (in our case the B type) avoid like-atom interactions with their neighbours, and that solvent-solute interactions are favoured and are greatest at the eutectic composition.

Another very similar model to that proposed here was put forward for liquid alloys of $\mathrm{Au}-\mathrm{Si}$ by Chen and Turnbull (1967), on the basis of thermodynamic evidence. Note here that these authors also attribute the low melting point at the eutectic composition to the stability of the liquid having been enhanced by A-B interactions.

Clearly it is not possible to define the liquid structures in precise terms, nor is it possible to state exactly the composition, (eutectic point or $A_{3} B$ ), at which the maximum number of $\mathrm{B}$ atoms can be accommodated in the close packed simple liquid structure. This model does however provide a clearer picture of the structure of binary liquid alloys than has been proposed hitherto.

\subsection{Some practical implications of expansion on solidification in the Au-based alloys}

The observations of volume expansion on solidification of the $\mathrm{Au}-\mathrm{Ge}$ and $\mathrm{Au}-\mathrm{Si}$ eutectic alloys, are of interest in the field of foundry metallurgy. For most materials a significant contraction on solidification occurs with consequent difficulties in obtaining sound castings. Alloys which could be developed, exhibiting either an expansion or no volume change on solidification, would be a great asset in the field of gold metallurgy. These would enable accurate castings of complex shapes to be made and would eliminate flash wastage.

\section{Acknowledgments}

The paper is based on results obtained in a programme of research supported by AERE, Harwell and subsequently by the South African Chamber of Mines. We are grateful to both bodies for permission to publish. Thanks are due to $\mathrm{Mr} \mathrm{B}$ W Mott of AERE and Dr T Groenwald of the Chamber of Mines for helpful discussions.

\section{References}

Ashcroft N W and Lekner J 1966 Phys, Rev. 14583

Breuil M and Tourand G 1970 J. Phys. Chem. Solids 31549

Chen H S and Turnbull D 1967 J. Appl. Phys. 383646

Enderby J E, North D M and Egelstaff P A 1966 Phil. Mag. 14961

Furukawa K, Orton B R, Hamor J and Williams G I 1963 Phil. Mag. 8141

Halder N C and Wagner C N J 1967 J. Chem. Phys. 474385

Heath E G 1961 J. Electron Control 1113 
Hume-Rothery W and Anderson E 1960 Phil. Mag. 5383

Isherwood S P, Manaila A and Orton B R 1972 J. Non. Cryst. Solids 8691

Isherwood S P and Orton B R 1972 J. Phys. C: Solid St. Phys. 52977

Jones H 1973 Rep. Prog. Phys. 361425

Kaplow R, Strong S L and Averbach B L 1965 Phys. Rev. 138 A 1336

1966 Metal Soc. Conf. 36159

Keating D T 1963 J. Appl. Phys. 34923

Klug H P and Alexander L E 1954 X-ray Diffraction Procedures (New York: Wiley) 607

Kumar R and Sivaramakrishnan C S 1969a J. Mater. Sci. 4377

- 1969b J. Mater. Sci. 4383

Mott B W 1967 AERE Report 5565

Orton B R $1964 P h D$ Thesis University of London

Orton B R, Shaw B A and Williams G I 1960 Acta Metall. 8177

Pfannenschmid O 1960 Z. Naturf. 15603

Powell G L F 1967 Trans AIME 2391663

Rodriguez S E and Pings C J 1965 J. Chem. Phys. 422435

Singh M and Kumar R 1966 Trans. Ind. Inst. Metals 19117

Turner R, Crozier E D and Cochran J F 1973 J. Phys. C: Solid St. Phys. 63359

Ubbelohde A R 1965 Melting and Crystal Structures, (Oxford: Clarendon) 171

Waghorne R M, Rivlin V G and Williams G I 1967 Adv. Phys. 16215

Waseda Y and Suzuki K 1975 Z. Phys. B 20339 